background, we must first think of its structure. The vessels which form the choroid are arranged in layers, increasing in fineness as they approach the anterior surface. The outermost layer, next the sclerotic, consists largely of the so-called vortices, or star-shaped groups of veins, each group meeting in a common centre. Contiguous veins, approaching such a centre, depart but little from parallelism, and are separated by interspaces about their own width, usually containing much pigment. In front of this layer is one of finer vessels, still arranged in a direction of general parallelism, or at most of very restricted arborescence, when contrasted with that of the vessels of the retina. In front of this finer layer is one composed of capillaries too fine to be individually visible; and in front of the capillaries there is a stratum of epithelial cells, each cell usually containing pigment granules. This epithelial layer lies immediately behind the retina, and is seen through it. We may easily use such a magnifying power as to obtain from the cells a certain granular aspect. If the cells are loaded with pigment, they are rendered completely opaque, and we see nothing beyond them. This may be regarded as the typical condition of the eyes of dark people, and it affords a uniform dark or dull-red background, on which the retinal vessels are seen to ramify, and which may be resolved by high magnifying powers into a finely granular surface.

\section{NOTES ON A \\ CASE OF CHRONIC HYDROTHORAX.} BY JOHN DEWAR, L.R.C.P.E., \&c.

A DESCRIPTION of the following case may not be uninteresting to the profession, as affording a good example of one of the rare forms of pleurisy. But it is not so much on account of its rarity, or even because of the different mode of treatment successfully adopted, that I wish to record it, as on account of its being a good illustration of what was long ago pointed out by Stoll, and inculcated in his Clinical Lectures by the late Professor Trousseau, but which, I fear, is not so prominently kept in view as the importance of the fact requires: namely, that latent pleurisies are very frequently manifestations of a tubercular diathesis-expressions of a phthisical taint. So that the occurrence of an attack of latent pleurisy without any apparent exciting cause, and especially if, as in the present case, there be a family history of consumption, should arouse the attention of the medical attendant, and excite his fears as to the ultimate issue of the case; he will thus be induced to use every effort, by warning the patient against colds, and by using prophylactic treatment, to arrest the insidious onset of pulmonary consumption. I shall first record the case from my notebook, and then make a few remarks.

Dec. 17th, 1868.-Mrs. B- a aged thirty-eight, a month ago was delivered of her fourth child, attended by a woman, and said to have had a rather difficult time-a dry labour, and "no great loss." Patient did not get up for three weeks after; but two or three days after she got about-or three days ago-she felt her breath begin to get short, and gradually getting worse, though up to the time of my visit she attempted to do her household duties. She now looks pale and anæmic, with an anxious expression of countenance, and is evidently suffering from great dyspnœa, which compels her to stop two or three times for breath during a sentence. Has no pain, cough, or expectoration. Never had any cough or shortness of breath before, nor, indeed, anything the matter with her, having been always "hearty." Complains of tightness over sternum going up to the left shoulder, but nothing amounting to pain. Pulse 132, and thready; skin cool; tongue clean; and bowels costive. Ordered to bed.-Physical signs: Very marked dulness over the whole left chest, front and back, reaching up to the clavicle, and not altered by position. No apparent enlargement of left side, and no bulging of intercostal spaces. Dulness not abrupt at middle of sternum, but shades off. Inspiratory movements of left side defective. Right side normal. On the left side the apex-beat cannot be felt any- where, but is quite distinct just under the right nipple, with heart's base towards mid-sternum,-giving one the idea of this being a case of transposition of organs. On auscultation, vesicular murmur is found to be entirely gone throughout the left side, front and back ; and, except near the sternum and in the intrascapular region, where there is tubular breathing, no sound whatever can be heard, healthy or morbid-not even ægophony. Heart-sounds barely detected left of sternum, hut distinct and normal, though weak, on right side. Breathing slightly puerile on right side. To take ten grains of hydrochlorate of ammonia, with two grains of sesquicarbonate of ammonia, every four hours. 18th.-Physical signs unaltered; lies on back. Slightest exertion increases the already severe dyspnœa. Pulse 135. 'To take twenty grains of the hydrochlorate, and ten grains of the sesquicarbonate every three hours; and calomel, with compound jalap powder, to relieve bowels, which are confined.

19th.-Breathing a little easier. Has perspired freely. Pulse 120, and a little stronger. Continue mixture, and weak brandy-and-water occasionally.

20th.-Breathing decidedly better, and vesicular under clavicle; bronchial elsewhere. Heart sounds begin to be audible about the left breast, and pulsations felt, though not so distinct as on the right side. Pulse 120. Mixture as before. Rub chest with croton-oil liniment, and take strong beef-tea with the stimulant.

21st.-Says she can breathe better, and take a deeper breath. Vesicular breathing over greater part of left side; apex beat at left breast. Pulse keeps at about 120 . Least exertion puts her out of breath, which is easy when quiet. Feels very weak. To take bark and ammonia, with plenty of nourishment.

Patient continued to improve every day. It is worthy of note that there was no bulging either of the left chest as a whole, or of the in tercostal spaces, though, judging from the physical signs, the amount of serum must have been great. But this is easily understood when we remember that the bulging depends partly on paralysis of intercostal muscles, and partly on serous effusion into surrounding tissues, and that that is not likely to take place when the effusion has been rapid (as it evidently was in this case), or when the pulmonary pleura only is affected. Whatever the explanation, the occurrence is not unfrequent, especially in advanced life. The absence of agophony is usual when the lung is much compressed by the effusion. So, too, the increased difficulty of breathing on the least exertion, as changing linen, may be accounted for by the heart being forced out of its place, the aorta and large vessels being twisted, and therefore the circulation to a certain extent impeded. The treatment, dictated by the weakness of pulse, and prostration of patient, was stimulant from the commencement: carbonate of ammonia and brandy, with large doses of muriate of ammonia, which latter produced powerful diaphoresis. No mercury was given beyond the five grains of calomel, with compound jalap powder as a cathartic. The hydrochlorate of ammonia would seem to have some effect on serous membranes, for it has been found useful in some kinds of ascites; but whether all its good can be explained by its diaphoretic or diuretic action, or whether it has some special power, is not clear; at all events it is deserving of further trial in similar cases.

June 3rd, 1870. - Was called in to see patient to-day. Says she has been in perfect health since last illness, about eighteen months ago, up till March of the present year, when she thinks she caught cold. Since then has had a cough, and slight shortness of breath, which gets worse. Has no appetite; has night-sweats, and gets very thin. Expectoration mixed slightly with pus. Dulness under left clavicle, and respiration harsh and imperfect. Finger-nails clubbed. Has lost four sisters under twenty-five years of age, from consumption.

Great Wakering, Essex, July, 1870.

A SEMI-Official account of the condition of the Prussian armies in France estimates the German effective strength (in France) at 600,000 men, of whom 250,000 are now before Paris. This report states that the German troops have at present 100,000 sick, and have lost since the beginning of the campaign, either in battles or in hospitals, 300,000 men. 